\section{Geographische Höhe als Einflussgröße}

W. G. Guder

München, Deutschland

Synonym(e) Höhe über Normalnull; Höhe über dem Meeresspiegel

Englischer Begriff altitude; altitude above sea level as influence factor

Definition Die geographische Höhe gibt die relative Höhe über dem mittleren Meeresspiegel an. Sie wird in Metern (m) angegeben.

Beschreibung Schon bald nach Entwicklung der labormedizinischen Diagnostik wurden Unterschiede in der Konzentration von Blut- und Urinbestandteilen zwischen Personen, die in verschiedener Meereshöhe wohnen, gemessen. Das bekannteste Beispiel ist die Hämoglobinkonzentration, die als Anpassung an die verminderte Sauerstoffkonzentration der Atemluft um $8 \%$ bei $1400 \mathrm{~m}$ Höhe ansteigt. Dabei ist zu unterscheiden zwischen Veränderungen durch kurzfristige Aufenthalte in großer Höhe und konstanten Unterschieden bei dauerndem Aufenthalt. Folgende Einflüsse wurden bei alpinistisch, sportlich oder touristisch in größeren Höhen Weilenden gefunden:

- $\downarrow$ Aldosteron

- $\downarrow$ Vasopressin (ADH)

- $\uparrow$ ANP (atriales natriuretisches Peptid)

- $\uparrow$ Kortisol und Katecholamine

- $\uparrow$ CRP (C-reaktives Protein)

- $\downarrow$ Reninaktivität

- $\downarrow$ Transferrin

- Zunächst $\downarrow$ Urinvolumen; $\uparrow$ nach 4 Tagen in großer Höhe

Demgegenüber finden sich niedrigere Werte für die KreatininClearance und höhere Kreatinin-Plasmakonzentrationen, höhere Harnsäurewerte parallel zur Hämoglobin- und Hämatokritkonzentration und niedrigere Albuminkonzentrationen und höhere $\gamma$-Globulinfraktion in der Elektrophorese bei über 6-wöchigem Aufenthalt in großer Höhe.

\section{Literatur}

Influences that can vary (diet, starvation, exercise, altitude) (2009) In: Guder WG, Narayanan S, Wisser H, Zawta B (Hrsg) Diagnostic Samples: from the Patient to the Laboratory. Wiley-Blackwell, Weinheim, S 10-11

Young DS (2007) Effects of Preanalytical Variables on Clinical Laboratory Tests, 3. ed. AACC Press, Washington, DC 